\section{Commentary: Learning points from a remarkable success in achieving stable pulmonary blood flow in a very small baby with Ebstein anomaly and a circular shunt}

\author{
Gananjay G. Salve, MS, MCh, ${ }^{\mathrm{a}}$ and \\ David S. Winlaw, MBBS, MD, FRACS ${ }^{b}$
}

Critical neonatal Ebstein anomaly with persistent circular shunt is a difficult and complex problem, with a perinatal mortality as high as $45 \% .{ }^{1}$ It is uncommon and frequently fatal. According to the Society of Thoracic Surgeons Congenital Heart Surgery Database (2015-2019), Ebstein anomaly constituted only $0.5 \%$ of all primary neonatal diagnoses, ${ }^{2}$ revealing its rare occurrence. It is difficult to know when to intervene: a Starnes procedure addresses the problematic physiology, but the management of the often sick, preterm, and very low birth weight baby after a bypass operation is further complicated by the myriad complexities of managing the systemic to pulmonary shunt.

Deng and colleagues ${ }^{3}$ did a remarkable job of rescuing a premature, very low birth weight neonate with Ebstein anomaly and persistent circular shunt. They performed a "rapid staged repair," which finally involved retention of the patent ductus arteriosus (PDA) and bilateral branch pulmonary artery (PA) bands to have a controlled pulmonary circulation instead of performing a modified Blalock-Taussig-Thomas (BTT) shunt, which commonly accompanies the modified Starnes procedure. This rescued the patient

From the a'Heart Centre for Children, The Children's Hospital at Westmead, Westmead, Australia; and ${ }^{\mathrm{b}}$ The Heart Institute, Cardiothoracic Surgery, Cincinnati Children's Hospital Medical Center, Cincinnati, Ohio.

Disclosures: The authors reported no conflicts of interest.

The Journal policy requires editors and reviewers to disclose conflicts of interest and to decline handling or reviewing manuscripts for which they may have a conflict of interest. The editors and reviewers of this article have no conflicts of interest.

Received for publication Feb 16, 2021; revisions received Feb 16, 2021; accepted for publication Feb 22, 2021; available ahead of print Feb 26, 2021.

Address for reprints: David S. Winlaw, MBBS, MD, FRACS, The Heart Institute, Cardiothoracic Surgery, Cincinnati Children's Hospital Medical Center, 3333 Burnet Ave, MLC 2013, Cincinnati, OH 45229-3026 (E-mail: david.winlaw@ cchmc.org).

JTCVS Techniques 2021;7:212-3

2666-2507

Copyright (C) 2021 The Authors. Published by Elsevier Inc. on behalf of The American Association for Thoracic Surgery. This is an open access article under the CC BY license (http://creativecommons.org/licenses/by/4.0/).

https://doi.org/10.1016/j.xjtc.2021.02.028

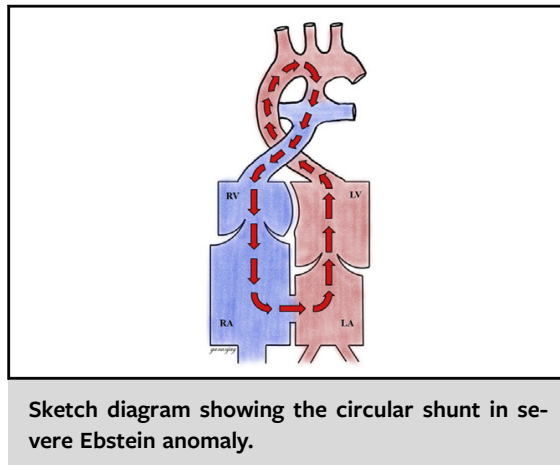

CENTRAL MESSAGE

Securing stable pulmonary blood

flow in a low-birth-weight baby

after a Starnes procedure is

difficult. Closing the main pul-

monary artery and banding the

pulmonary arteries is a good

interim stage.

with a short period of extracorporeal membrane oxygenation. A modified BTT shunt was eventually done 3 months later along with takedown of PA bands and PDA ligation.

The authors used this approach after initial PA ligation and right atrial reduction failed to stabilize the baby. It would be reasonable to move straight to main PA ligation and PA banding along with right ventricular exclusion in future cases. It is easy to make this suggestion in retrospect, and we acknowledge this group's experience in this condition. Nevertheless, in management of Ebstein anomaly, sometimes an early and substantial intervention is the best way to correct an otherwise downward trajectory, particularly when a circular shunt exists. This needs to be balanced against the well-justified approach of medical management only-improving forward flow by lowering pulmonary resistance, improving right ventricular function, and allowing progressive ductal closure. Perhaps the message here is, if something is required to be done, be sure to make it as definitive as possible.

There have been a number of reports using this approach in severe neonatal Ebstein anomaly with circular shunt. ${ }^{4}$ One of the reported patients required a PDA stent and survived through the subsequent stages, whereas the other died. Another case report mentions use of bilateral branch 
PA banding with PDA for a short period of 4 days, after which it was converted to a Starnes procedure with a modified BTT shunt. ${ }^{5}$ The variability in outcomes highlights the fragility of these neonates, the difficulties involved in achieving a stable circulation, and the fact that PA banding with an open duct is not a panacea, making the reported outcome all the more noteworthy.

\section{References}

1. Freud LR, Escobar-Diaz MC, Kalish BT, Komarlu R, Puchalski MD, Jaeggi ET, et al. Outcomes and predictors of perinatal mortality in fetuses with Ebstein anomaly or tricuspid valve dysplasia in the current era: a multicenter study. Circulation. 2015;132:481-9.

2. Mayer JE, Hill K, Jacobs JP, Overman DM, Kumar SR. The Society of Thoracic Surgeons Congenital Heart Surgery database: 2020 update on outcomes and research. Ann Thorac Surg. 2020;110:1809-18.

3. Deng MX, Kirsch R, Jaeggi E, Honjo O. Management of a premature low birth weight neonate with Ebstein anomaly and persistent circular shunt using modified Starnes procedure. J Thorac Cardiovasc Surg Tech. 2021;7:208-11.

4. Elzein C, Subramanian S, Ilbawi M. Surgical management of neonatal Ebstein's anomaly associated with circular shunt. World J Pediatr Congenit Heart Surg. 2019;10:116-20.

5. Hasegawa M, Iwai S, Yamauchi S, Kugo Y, Kayatani F, Takahashi K, et al. Bilateral pulmonary artery banding in Ebstein's anomaly with circular shunting. Ann Thorac Surg. 2019;107:e317-9. 